\title{
Comparison of the indirect fluorescent antibody test with agglutination, complement-fixation, and Coombs tests for Brucella antibody
}

\author{
JOAN M. B. EDWARDS, AGNES J. TANNAHILL, AND C. M. PATRICIA
} BRADSTREET

From the Standards Laboratory for Serological Reagents, Central Public Health Laboratory, Colindale, London

SYNOPSIS A comparison is made of a Brucella fluorescent antibody test with four standard tests on 342 normal, 86 diagnostic, and 41 known positive human sera. Where positive titres of accepted significance were obtained in standard tests, a titre of $1 / 10$ or more was achieved in the fluorescence test.

The Standards Laboratory for Serological Reagents has been concerned with the assessment of antispecies globulin fluorescein conjugates for use in public health laboratories. Among the tests developed for this purpose was one using Brucella suspension and positive control serum. Between 1965 and 1968 a large number of sera were collected by the Public Health Laboratory Service Working Party on Brucellosis and 1,500 were to be examined in the Standards Laboratory for the presence of Brucella antibody by complement-fixation, agglutination, 2-mercaptoethanol agglutination, and Coombs tests. The opportunity was taken to apply the indirect fluorescent antibody test to some of these at the same time so that its value could be compared with other tests. In addition a number of convalescent sera were available and these were subjected to all five tests.

This paper reports the procedures and the results obtained and comments on the comparative value of the indirect fluorescent antibody test.

\section{Materials and Methods}

SERA

The fluorescent antibody test was applied to 428 of the sera being examined for the Working Party. Of these sera, 342 were paired samples from Received for publication 23 April 1969
171 presumed normal adults living in various $\Phi$ areas of England and Wales, and 86 were paired samples from 43 people who were ill and suspected of suffering from brucellosis. One of each pair of samples was collected before, and the other three to four weeks after, a brucellin skin test was performed. Neither of these types? of sera was deliberately selected for the fluorescent antibody test.

Sera with an agglutination titre of $1 / 160$ or more, obtained from patients diagnosed as suffering from brucellosis, are sent to the 옥 Standards Laboratory from laboratories in $\rightarrow$ England and Wales for the preparation of the positive control serum for the Brucella aggluti- No nation test. These sera are refrigerated at $4{ }^{\circ} \mathrm{C}$ until pooled and freeze dried. The five tests were $\mathcal{O}$ applied to 41 of these convalescent sera which $\omega$ were in store at the time this work was undertaken.

\section{ANTIGEN}

The Standards Laboratory Brucella abortus concentrated suspension, of an opacity equivalent to $8,000 \times 10^{6}$ Escherichia coli per millilitre, was used for the agglutination tests. The same suspension was diluted $1 / 60$ with veronal buffer 8 for the complement-fixation test and diluted 1/8 with phosphate-buffered saline, $p \mathbf{H} 7 \cdot 2$, for the fluorescent antibody test. 
SEROLOGICAL REAGENTS

For the Coombs test the Coombs reagent (AHG) supplied by Burroughs Wellcome \& Company was used at a dilution of $1 / 16$, giving a final dilution of $1 / 160$ in the test. For the fluorescence tests two batches of an antihuman globulin (Caprine) F.I.T.C. conjugate prepared by Baltimore Biological Laboratories were used at a dilution of $1 / 20$. This dilution had been found satisfactory in the fluorescent treponemal antibody-200 test (US PHS, 1964) and in the Brucella test developed for assessment of indirect fluorescent conjugates in the Standards Laboratory. The serum used as a control in the fluorescence tests was the current batch of positive control serum for agglutination tests. This serum has an agglutination titre of $1 / 640$. In the fluorescence test it was used at a dilution of $1 / 10$. A negative serum was used at the same dilution for the negative control.

\section{METHODS}

All sera were first made up as a master dilution of $1 / 10$ in saline. Further dilutions were made in the diluent appropriate for each test. Tests 1 to 4 were begun on the same day. For convenience the fluorescence test was performed on the original $1 / 10$ dilution on the following day. This dilution was stored at $4^{\circ} \mathrm{C}$ between tests. Comparative tests showed that no alteration in titre resulted from such storage.

\section{Agglutination test (AGGL)}

The technique used is described in Memorandum No. 4 of the Public Health Laboratory Service (1961). The water bath incubation period used was extended to 48 hours. In $1 \mathrm{ml}$ amounts of $0.4 \%$ phenol saline doubling dilutions of serum were made beginning with a dilution of $1 / 20$ using $50.8 \mathrm{~mm} \times 12.7 \mathrm{~mm}\left(2\right.$ in. $\times \frac{1}{2}$ in. $)$ tubes. To each tube $0.05 \mathrm{ml}$ of concentrated antigen was added and after shaking the test was incubated in a water bath at $37^{\circ} \mathrm{C}$. Readings from +++ to $(( \pm))$ were made, taking into account the aggregation of deposit, clearing of supernatant, and the size of the aggregates after agitation of the tube. The titre of the serum was recorded as the last tube showing + or agglutination readily visible to the naked eye after gentle shaking. If the tubes are not shaken this aggregation may be missed, particularly at low dilutions of opaque sera which do not readily show clearing of the supernatant.

\section{2-Mercaptoethanol test (2-ME)}

The same technique was used for this agglutination test but the phenol saline diluent was replaced by $0.05 \mathrm{M}$ 2-mercaptoethanol in saline.

Coombs test

For reasons of economy of labour and materials a third agglutination test was not set up for this test. It therefore varied from the usual Coom test for brucellosis in that the antigen was weake and it was performed after 48 rather than 24 hours' incubation. All tubes found negative the standard agglutination test after 48 hours incubation in a water bath at $37^{\circ} \mathrm{C}$ were cent fuged and, after discarding the supernatant, the deposit was vigorously resuspended in 0.5 refl saline. This centrifugation and resuspension wo repeated twice. A final centrifugation w followed by resuspension in $0.5 \mathrm{ml}$ of $0.4 \%$ phenol saline. Then $0.05 \mathrm{ml}$ Coombs reagent whss added to each tube. The tubes were incubated $\overrightarrow{a t}$ $37^{\circ} \mathrm{C}$ for 24 hours. The titre was taken as the last tube showing clearing.

\section{Complement-fixation test (CFT)}

The technique used was that described Bradstreet and Taylor (1962). This techniquis used overnight fixation and a dose of $3 \mathrm{HD}_{50}$ of complement. The microtechnique was employed for some of the tests in which $0.025 \mathrm{ml}$ volumes of reagents were used in a WHO Perspex plate covered by a tight-fitting plastic lid to preveñ evaporation.

\section{Fluorescent antibody test $(F A)$}

Three well spaced circles, $3.0 \mathrm{~mm}$ in diametes, were marked with a diamond on clean thin slides. Each circle was filled with antigen from a $3 \mathrm{~m}$ loop. After drying in air these smears were fixe by passing the slide rapidly through a flame, These slides were used for the indirect fluorescer. antibody test. Doubling dilutions from 1/10 to $1 / 320$ were made of the human serum to tested and $0.025 \mathrm{ml}$ of each of the six dilutions was transferred to the six smears on a pair $\overrightarrow{\text { of }}$ slides using the complement-fixation test microtechnique dropper. The slides were incubated a closed moist box at $37^{\circ} \mathrm{C}$ for $30 \mathrm{~min}$, and the washed vigorously in phosphate-buffered saline at $p \mathrm{H} \mathrm{7.2}$ for 10 minutes. The slides were dried in air and $0.01 \mathrm{ml}$ of a 1/20 dilution of ants human globulin fluorescein conjugate was applie to each antigen-serum spot and the slides we again incubated in a closed moist box for 30 min at $37^{\circ} \mathrm{C}$. They were then washed in the phosphate buffer for $10 \mathrm{~min}$, dried and the smeats mounted with polar-fluor B under a long covetslip. Fluorescence was read using the equipmen described by Lidwell, Taylor, Clark, and Heime्g (1967) and degrees from +++ to negative wefe recorded. A reading of ++ was given when the fluorescent outer rim of the bacillus could just te distinguished from the non-fluorescent inne body. This was taken as the titre of the human serum. Positive and negative control sera were used with each batch of tests to standardize the readings from day to day. This full fluorescen@e test was performed only on sera showing + reading or more with a preliminary screenis test using the human serum at $1 / 10$. The technique 
for the screening test was otherwise as described above.

\section{Results}

These are presented in Tables I to V. Only 18 of the 342 sera from normal people showed a positive fluorescence titre of $1 / 10$. These people came from the Preston, Truro, or Wolverhampton areas where exposure to brucellosis might be expected. Ten of these fluorescence-positive sera were pairs from five individuals obtained before and after a brucellin skin test. The other eight were all the second specimens obtained after a skin test. The complement-fixation and 2mercaptoethanol agglutination reactions were positive in 14 and 16 respectively of these 18 specimens, and an agglutination or Coombs titre of $1 / 80$ or over was recorded in 10 and 16 respectively (Table I).

\begin{tabular}{lccccc}
\hline Titre & \multicolumn{7}{c}{$\begin{array}{l}\text { No. of Sera } \\
\text { Shown }\end{array}$} \\
\cline { 2 - 6 } & FA & CFT & AGGL & $2-M E$ & Coombs $^{1}$ \\
\hline Results for 18 sera & positive by & fluorescence & test \\
$1 / 10$ & 18 & - & - & - & - \\
$1 / 20$ & 3 & 14 & 16 & 16 & 18 \\
$1 / 40$ & 2 & 10 & 15 & 13 & 18 \\
$1 / 80$ & - & 5 & 10 & 6 & 16 \\
$1 / 160$ & - & 4 & 6 & 3 & 14 \\
$1 / 320$ & - & 4 & 3 & 2 & 9 \\
$1 / 640$ & - & 1 & 2 & - & 4 \\
$1 / 1280$ & - & - & 2 & - & 2 \\
Total positive from & & & & & \\
18 specimens & 18 & 14 & 16 & 16 & 18 \\
Results for 324 sera & negative by & fluorescence test & \\
$1 / 20$ & - & 17 & 71 & 20 & 83 \\
$1 / 40$ & - & - & 34 & 4 & 55 \\
$1 / 80$ & - & - & 6 & - & 25 \\
$1 / 160$ & - & - & 2 & - & 4 \\
$1 / 320$ & - & - & - & - & 2 \\
$1 / 640$ & - & - & - & - & - \\
Total positive from & & & & & \\
110 specimens & - & 17 & 71 & 20 & 83 \\
\hline
\end{tabular}

Table I Results of tests on 342 sera from normal individuals participating in a brucellin skin test survey

${ }^{1}$ In the three tests where the Coombs procedure did not produce a positive reaction the titre recorded is the same as the agglutination test result.

Among the 324 specimens with a negative fluorescence reaction, 214 were negative in all other tests; 110 showed a positive in some other test. Most of these were positive only at the lowest titres. Only 13 had a positive reaction in three tests and two in all four (Table I).

Table II shows the results of tests in 86 sera from 43 cases in which the possibility of brucellosis was considered sufficiently likely for a diagnostic brucellin skin test to be performed by the clinician. Thirteen specimens had a positive fluorescence reaction. Ten of these were paired sera from five patients showing clear

\begin{tabular}{|c|c|c|c|c|c|}
\hline \multirow[t]{2}{*}{ Titre } & \multicolumn{5}{|c|}{$\begin{array}{l}\text { No. of Sera Positive in Each Test at Titre } \\
\text { Shown }\end{array}$} \\
\hline & $F A$ & CFT & $A G G L$ & $2-M E$ & Coombs ${ }^{1}$ \\
\hline \multicolumn{6}{|c|}{13 sera positive by fuorescence test } \\
\hline $1 / 10$ & 13 & - & - & - & - \\
\hline $1 / 20$ & 6 & 13 & 13 & 12 & 13 \\
\hline $1 / 40$ & 4 & 8 & 13 & 11 & 13 \\
\hline $1 / 80$ & 3 & 4 & 12 & 6 & 13 \\
\hline $1 / 160$ & - & 4 & 8 & 4 & 13 \\
\hline $1 / 320$ & - & 4 & 4 & 4 & 11 \\
\hline $1 / 640$ & - & 1 & 1 & 1 & 6 \\
\hline $1 / 1280$ & - & - & - & - & - \\
\hline \multicolumn{6}{|c|}{ Total positive from } \\
\hline 13 sera & 13 & 13 & 13 & 12 & 13 \\
\hline \multicolumn{6}{|c|}{73 sera negative by fluorescence test } \\
\hline $1 / 20$ & - & - & 12 & - & 20 \\
\hline $1 / 40$ & - & - & 3 & - & 8 \\
\hline $1 / 80$ & - & - & - & - & 3 \\
\hline $1 / 160$ & - & - & - & - & 3 \\
\hline $1 / 320$ & - & - & - & - & - \\
\hline \multicolumn{6}{|c|}{ Total positive from } \\
\hline
\end{tabular}

Table II. Results of tests on 86 sera from patients with a diagnosis of possible brucellosis

${ }^{1}$ In two tests where the Coombs procedure did not produce a positive reaction the titre recorded is the same as the agglutination test result.

positive reactions in all the standard and fluorescence tests at the time that the diagnostic skin test was requested. Three patients had a positive fluorescence reaction in the post-brucellin specimen only, and in these patients the standard tests gave an equivocal result in the serum obtained before the skin test. One had an agglutination titre of $1 / 40$ and a Coombs titre of $1 / 160$; the complement-fixation and 2-mercaptoethanol tests were negative at $1 / 20$. The other two sera gave negative reactions except for a Coombs titre of $1 / 20$ and $1 / 40$ respectively.

In Table II, among 73 sera with a negative fluorescence test, 53 were negative in all other tests. No sera gave positive 2-mercaptoethanol or complement-fixation tests. Threesera gave Coombs titres of $1 / 160$ combined with an agglutination titre of $1 / 20$ or $1 / 40$. One of these was the first specimen of a pair, taken before the skin test. The second specimen of the pair, taken after the skin test, appears among the fluorescent-positive sera. The remaining 17 sera gave positive titres of less than 1/80 in Coombs or agglutination tests, seven of them in both tests.

In Table III a full comparison has been made of the results of all the tests on each serum specimen which had been sent to us because it had a positive agglutination titre of $1 / 160$ or more. The first few sera have a very low titre in all tests. It is possible that these had deteriorated during storage. Three of these specimens happened to be a very small quantity. These results are arranged in order of fluorescence titre and are set out in full for each individual serum to allow detailed study.

A small reproducibility test was performed by accident. Specimens 1 to 7 were found, after testing, to be one specimen distributed into seven 


\begin{tabular}{|c|c|c|c|c|c|}
\hline \multirow{2}{*}{$\begin{array}{l}\text { Specimen } \\
\text { No. }\end{array}$} & \multicolumn{5}{|c|}{ Reciprocals of Titres for Each Test } \\
\hline & $F A$ & $A G G L$ & 2-ME & Coombs ${ }^{1}$ & CFT \\
\hline 24 & 10 & 40 & 40 & $<20$ & $<20$ \\
\hline 44 & 10 & 160 & 20 & 160 & $<20$ \\
\hline 48 & 10 & 40 & 40 & 40 & $<20$ \\
\hline 39 & 10 & 40 & 20 & 160 & $<20$ \\
\hline 34 & 10 & $<20$ & $<20$ & 80 & $<20$ \\
\hline 36 & 10 & 20 & $<20$ & - & $<20$ \\
\hline 54 & 10 & 160 & 40 & 320 & $<20$ \\
\hline 47 & 10 & 160 & 80 & 160 & 20 \\
\hline 28 & 10 & 160 & 20 & 640 & 20 \\
\hline 45 & 10 & 40 & 40 & 320 & 40 \\
\hline 39965 & 10 & 80 & 40 & 160 & 40 \\
\hline 33 & 10 & 80 & 80 & - & 40 \\
\hline 42 & 10 & 2,560 & 80 & 5,120 & 20 \\
\hline 25 & 10 & 640 & 20 & 1,280 & 40 \\
\hline 49 & 10 & 160 & 320 & 640 & 160 \\
\hline 30 & 20 & 640 & 80 & 1,280 & 40 \\
\hline 22 & 20 & 160 & 40 & 640 & 80 \\
\hline 13 & 20 & 160 & 80 & 320 & 160 \\
\hline 26 & 20 & 1,280 & 40 & 2,560 & 160 \\
\hline 14 & 20 & 160 & 160 & 1,280 & 320 \\
\hline 35 & 20 & 320 & 80 & 640 & 80 \\
\hline 8 & 40 & 320 & 320 & 2,560 & 80 \\
\hline 31 & 40 & 320 & 80 & 640 & 160 \\
\hline 40 & 40 & 320 & 160 & 1,280 & 320 \\
\hline 27 & 40 & 160 & 320 & - & 640 \\
\hline 17 & 80 & 320 & 160 & 640 & 80 \\
\hline 43 & 80 & 1,280 & 160 & 5,120 & 160 \\
\hline 41 & 80 & 320 & 320 & 1,280 & 320 \\
\hline 20 & 80 & 320 & 1,280 & $>2,560$ & 640 \\
\hline 52 & 80 & 640 & 80 & 1,280 & 640 \\
\hline 38 & 80 & 320 & 320 & 640 & 640 \\
\hline 11 & 80 & 320 & 640 & 1,280 & 1,280 \\
\hline 57 & 80 & 320 & 160 & 2,560 & $>1,280$ \\
\hline 23 & 80 & 640 & 640 & 10,240 & $>1,280$ \\
\hline Taylor & 80 & 2,560 & 640 & - & $>1,280$ \\
\hline $1-7^{2}$ & 160 & 320 & 640 & 1,280 & 640 \\
\hline 50 & 160 & 640 & 160 & 2,560 & 320 \\
\hline 9 & 160 & 160 & 160 & 1,280 & 640 \\
\hline 51 & 320 & 1,280 & 320 & - & 160 \\
\hline 29 & 320 & 640 & 640 & 1,280 & 640 \\
\hline 46 & 320 & 1,280 & 2,560 & - & 1,280 \\
\hline
\end{tabular}

Table III Forty-one sera sent for pooling as standard Brucella-positive control serum

IIn three tests where the Coombs procedure did not produce a positive reaction the titre recorded is the same as the agglutination test result.

${ }^{2}$ This specimen was received in seven different bottles and the contents of each bottle were examined separately. The results are given in detail in Table IV; the titre given in this table is the modal titre from Table IV.

\begin{tabular}{llllll}
\hline & $F A$ & $A G G L$ & $2-M E$ & Coombs & CFT \\
\hline 1 & $1 / 80$ & $1 / 320$ & $1 / 640$ & $1 / 1,280$ & $1 / 320$ \\
2 & $1 / 160$ & $1 / 640$ & $1 / 640$ & $1 / 1,280$ & $1 / 320$ \\
3 & $1 / 80$ & $1 / 320$ & $1 / 320$ & $1 / 1,280$ & $1 / 640$ \\
4 & $1 / 160$ & $1 / 320$ & $1 / 640$ & $1 / 1,280$ & $1 / 640$ \\
5 & $1 / 80$ & $1 / 320$ & $1 / 640$ & $1 / 1,280$ & $1 / 640$ \\
6 & $1 / 160$ & $1 / 640$ & $1 / 320$ & $1 / 2,560$ & $1 / 640$ \\
7 & $1 / 160$ & $1 / 320$ & $1 / 320$ & $1 / 1,280$ & $1 / 640$ \\
\hline
\end{tabular}

Table IV Results on seven samples of a single specimen all tested separately in the belief that they were seven different sera

serum bottles and not, as was thought at the time of the test, one specimen from each of seven different people. Sera 1 to 6 were examined on one day and specimen 7 four weeks later. The results of these tests are in Table IV which shows excellent reproducibility in all tests.

In Table $V$ the results of the four tests on each of the 41 sera appearing in Table III are compared. For each fluorescence titre the titre for each of the other tests has been plotted separately.

\section{Discussion}

The comparative value of the conventional tes? for the detection of Brucella antibody is being considered, using much larger numbers of specimens, by the Public Health Laborato Service Working Party on Brucellosis and widl not be discussed in this paper. The value of the fluorescent antibody test and its relation to these other tests is discussed.

The results in Table III as plotted in Table $\frac{d}{\mathrm{~V}}$ suggest that the relationship between fluorescent antibody titre and 2-mercaptoethanol aggluti? nation titre has the best rectilinear fit with the complement-fixation titre a close second. The is a suggestion of a curvilinear relationsh between fluorescent antibody titre and coms plement-fixation titre which is much mof marked with the Coombs titres. This may be influenced by the practice of recording very high titres as 'greater than' some titre where no further dilutions were included in the tests and the exact endpoint was not pursued by further tests. The agglutination titre shows the widest scatter an the least suggestion of a close relationship.

The tests usually considered to indicate the IgG level are the complement-fixation test and 2-mercaptoethanol agglutination, whereas staro dard agglutination and Coombs tests are als influenced by IgM or IgA levels. The results wit the convalescent sera suggest that the fluorescent antibody reaction in this series indicates the Ig level. Specimens nos. 25 and 42, and to a less extent no. 26, in Table III are of particula interest because the fluorescent antibody, complement-fixation, and 2-mercaptoethanol agglut nation titres are all low whereas the standard agglutination and Coombs titres are higher.

The conjugates used in these tests are made for routine diagnostic use and would be expected contain predominantly antihuman IgG. Co jugates of antihuman globulin sera specific for IgG, IgM, and IgA might be useful for the detailed study of the chronic type of case described by Kerr, Coghlan, Payne, and Rober. son (1966), and Kerr, Payne, Robertson, and Coombs (1967), where IgG and IgA antibodies were shown to be present but little IgM.

If a specimen arrives sufficiently early in thê day a result can be obtained by the fluoresce antibody test within two hours, but continuows attention is required during this period. Con plement-fixation and agglutination tests requife less working time. A complement-fixation tesit result can be obtained in 18 to 24 hours, and 9 provisional agglutination reading can be made 24 hours although 48 hours are required for the development of the full titre.

It is possible that examination of the patients serum at a dilution lower than $1 / 10$ would provis a positive result earlier in the disease. It was net possible to assess this point in this series becauss few of the sera were obtained at an early stage of 


\begin{tabular}{|c|c|c|c|c|c|c|c|c|c|}
\hline \multirow{2}{*}{$\begin{array}{l}\text { Fluorescent } \\
\text { Antibody } \\
\text { Reciprocals } \\
\text { of Titre }\end{array}$} & \multicolumn{9}{|c|}{ Numbers of Sera Positive at Titre } \\
\hline & $<20$ & 20 & 40 & 80 & 160 & 320 & 640 & 1,280 & $>1,280$ \\
\hline & \multicolumn{9}{|c|}{ Complement fixation } \\
\hline 10 & 7 & 3 & 4 & - & 1 & - & - & - & - \\
\hline 20 & - & - & 1 & 2 & 2 & 1 & - & - & - \\
\hline 40 & - & - & - & 1 & 1 & 1 & 1 & - & - \\
\hline 80 & - & - & - & 1 & 1 & 1 & 3 & 1 & 3 \\
\hline 160 & - & - & - & - & - & 1 & 2 & - & - \\
\hline \multirow[t]{2}{*}{320} & - & - & - & - & 1 & - & 1 & 1 & - \\
\hline & \multicolumn{9}{|c|}{ 2-Mercaptoethanol agylutization } \\
\hline 10 & 3 & 4 & 4 & 3 & - & 1 & -- & - & - \\
\hline 20 & - & - & 2 & 3 & 1 & -.. & - & - & - \\
\hline 40 & - & - & - & 1 & 1 & 2 & - & - & - \\
\hline 80 & - & - & - & 1 & 3 & 2 & 3 & 1 & - \\
\hline 160 & - & - & - & - & 2 & - & 1 & - & - \\
\hline \multirow[t]{2}{*}{320} & - & - & - & - & - & 1 & 1 & - & 1 \\
\hline & \multicolumn{9}{|c|}{ Agglutination } \\
\hline 10 & 1 & 1 & 4 & 2 & 5 & - & 1 & - & 1 \\
\hline 20 & - & - & - & - & 3 & 1 & 1 & 1 & - \\
\hline 40 & - & - & - & - & 1 & 3 & - & - & - \\
\hline 80 & - & - & - & - & - & 6 & 2 & 1 & 1 \\
\hline 160 & - & - & - & - & 1 & 1 & 1 & - & -- \\
\hline \multirow[t]{2}{*}{320} & - & - & - & - & - & - & 1 & 2 & - \\
\hline & \multicolumn{9}{|c|}{ Coombs ${ }^{1}$} \\
\hline 10 & 1 & - & 1 & 1 & 4 & 2 & 2 & 1 & 1 \\
\hline 20 & - & - & - & -- & - & 1 & 2 & 2 & 1 \\
\hline 40 & - & - & - & - & - & - & 1 & 1 & 1 \\
\hline 80 & - & - & -- & - & - & - & 2 & 3 & 4 \\
\hline 160 & - & - & - & - & - & -- & - & 2 & 1 \\
\hline 320 & - & - & - & - & - & - & - & 1 & - \\
\hline
\end{tabular}

Table $\mathrm{V}$ Numbers of sera positive in each test at a given titre from Table III charted against the fluorescence titre

${ }^{1}$ Six sera were not tested.

the illness and only a master dilution of $1 / 10$ was available for the fluorescence test. The three first specimens of pairs in which the second specimen was positive in Table II might have given a positive result at a dilution below $1 / 10$ but the result might be as difficult to interpret as the positive Coombs tests of $1 / 20$ and $1 / 40$. Similarly a positive fluorescent antibody test at $1 / 5$ might have provided additional positive information in the case in which only an agglutination titre of $1 / 40$ and Coombs titre of $1 / 160$ were present. However, at a serum dilution of $1 / 5$, many more fluorescent antibody tests may atso be positive in symptom-free people who have low levels of antibody in the other tests. As shown in the study of farmers and veterinarians by Foley and Corridan (1968), and in the work of Brodie and Gordon (1967) on blood donors in the Orkney Islands, the threshold titre of diagnostic significance is difficult to assess in all tests.

The fluorescent antibody test in this series, when positive, gives a good indication that other tests will be positive. This is in agreement with the results of Biegeleisen, Bradshaw, and Moody (1962). It appears to have no particular advantage over other tests except speed. If, however, large numbers of sera are to be tested in a survey screening by the fluorescent antibody technique might be invaluable. At a dilution of serum of $1 / 10$ no false positives were found. A screening dilution of $1 / 5$ or $1 / 8$ might be worth investigating.
In Table $I$ it will be seen that the final fluors: escence titre of 15 out of 18 sera is $1 / 10$ and in the complement-fixation test and 2-mercaptoethand] agglutination tests nine and 10 sera respectivedy of the same 18 have final titres of $1 / 20$ or $1 / 4 \bar{g}$. In Tables II and III it is clear that the titre in the complement-fixation and 2-mercaptoethan $\overline{\bar{a}}$ 1 tests is often two- or four-fold above the titre the fluorescence test at this level. In Table there are 17 positive complement-fixation tesws and 202 -mercaptoethanol tests positive at $1 / 20$. Among these as many as half might be positixe by fluorescence test at $1 / 5$, that is, 10 in 324 or approximately $3 \%$ of 'normal' individuals. Thäs gives some indication of the possible false positive rate by screening at $1 / 5$.

We wish to thank Mr J. Essex and Mrs D. Marrinfet for their capable technical and secretarial assistance, and the Public Health Laboratory Service Working Party on Brucellosis for the opportunity to investygate the sera.

\section{References}

Biegeleisen, J. Jr, Bradshaw, B. R., and Moody, M. D. (1962) Demonstration of brucella antitodies in human serum. A comparison of the fluorescent antibody and agglutinatien
techniques. J. Immunol., 88, 109-112.

Bradstreet, C. M. P., and Taylor, C. E. D. (1962). Technique complement-fixation test applicable to the diagnosis virus diseases. Mth. Bull. Minist. Hlth Lab. Serv., 96-104.

Brodie, J., and Gordon, R. M. (1967). Brucellosis in the Orkney Islands. Hlth. Bull (Edinb.), 25, 12-17.

Foley, B. V., and Corridan, J. P. (1968). Occupational brucello in County Cork. Brit. J. industr. Med., 25, 126-130.

Kerr, W. R., Coghlan, J. D., Payne, D. J. H., and Robertson, (1966). The laboratory diagnosis of chronic brucellosiर. Lancet, 2, 1181-1183.

Kerr, W. R., Payne, D. J. H., Robertson, L., and Coombs, R. R. A. (1967). Immunoglobulin class of Erucella andbodies in human sera. Immunol., 13, 223-225.

Lidwell, O. M., Taylor, C. E. D., Clark, S. P., and Heimé, G. V. (1967). Improved optical equipment for immuna: fluorescence studies. J. clin. Path., 20, 214-216.

Public Health Laboratory Service (1961). Serological reageno for bacteriological diagnosis. Mth. Bull. Minist. Hith Lad. Serv., 20, 134-149.

United States, Department of Health, Education and Welfate (1964). Serologic Tests for Syphilis. (Public Health Service Bulletin, no. 411). Government Printing Office, Washir ton, D.C. 